\title{
Correction to: Abaloparatide effect on forearm bone mineral density and wrist fracture risk in postmenopausal women with osteoporosis
}

\author{
N. B. Watts ${ }^{1} \cdot$ G. Hattersley ${ }^{2} \cdot$ L. A. Fitzpatrick ${ }^{2} \cdot$ Y. Wang ${ }^{2} \cdot$ G. C. Williams ${ }^{2} \cdot$ P. D. Miller ${ }^{3} \cdot$ F. Cosman ${ }^{4}$
}

Published online: 12 June 2020

(C) The Author(s) 2020

Correction to: Osteoporosis International (2019) 30:1187-1194

https://doi.org/10.1007/s00198-019-04890-2

The original version of this article, published on 21 March 2019, unfortunately contains some typos in Figs. 2, 3, 4, and Supplemental Fig. 1. The corrected figures are given below.

The online version of the original article can be found at https://doi.org/ 10.1007/s00198-019-04890-2

Electronic supplementary material The online version of this article (https://doi.org/10.1007/s00198-020-05469-y) contains supplementary material, which is available to authorized users.

N. B. Watts

nelson.watts@hotmail.com

1 Mercy Health Osteoporosis and Bone Health Services, Cincinnati, OH, USA

2 Radius Health, Inc., Waltham, MA, USA

3 Colorado Center for Bone Research, Lakewood, CO, USA

4 Columbia University College of Physicians and Surgeons, New York, NY, USA 
a

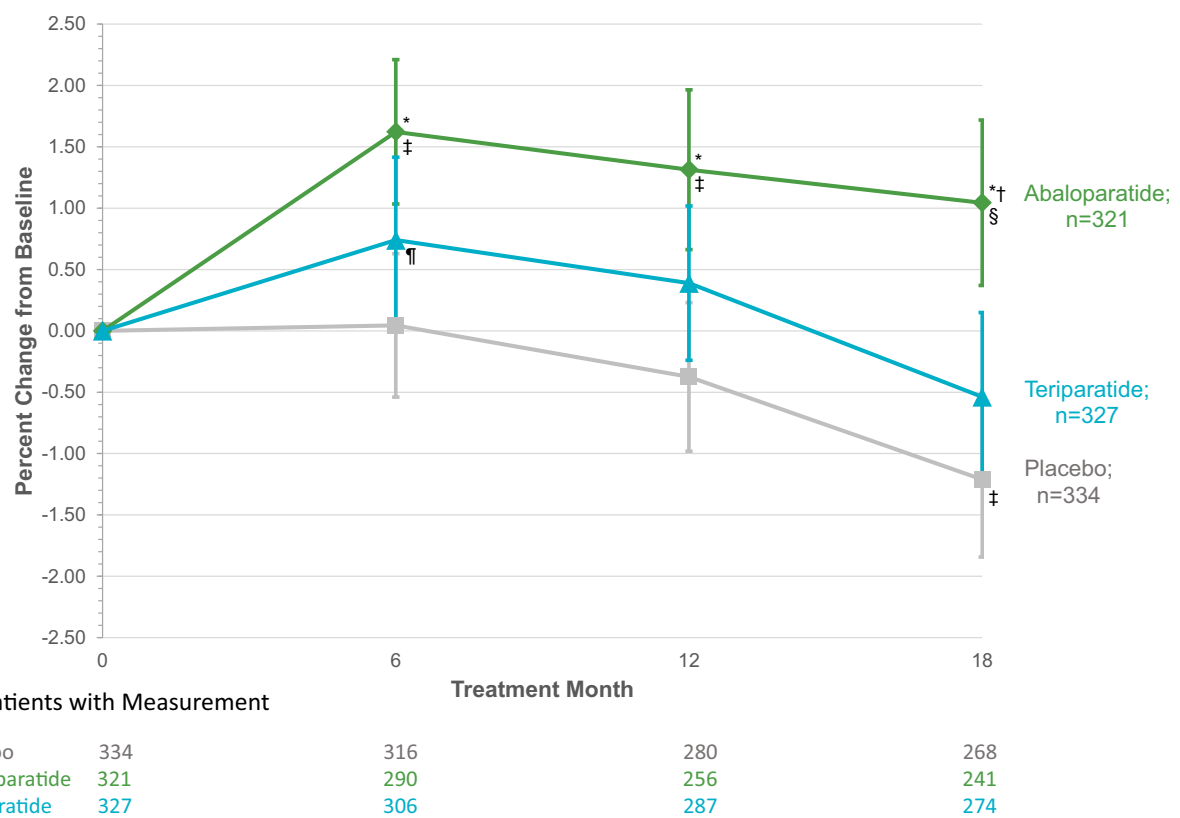

b

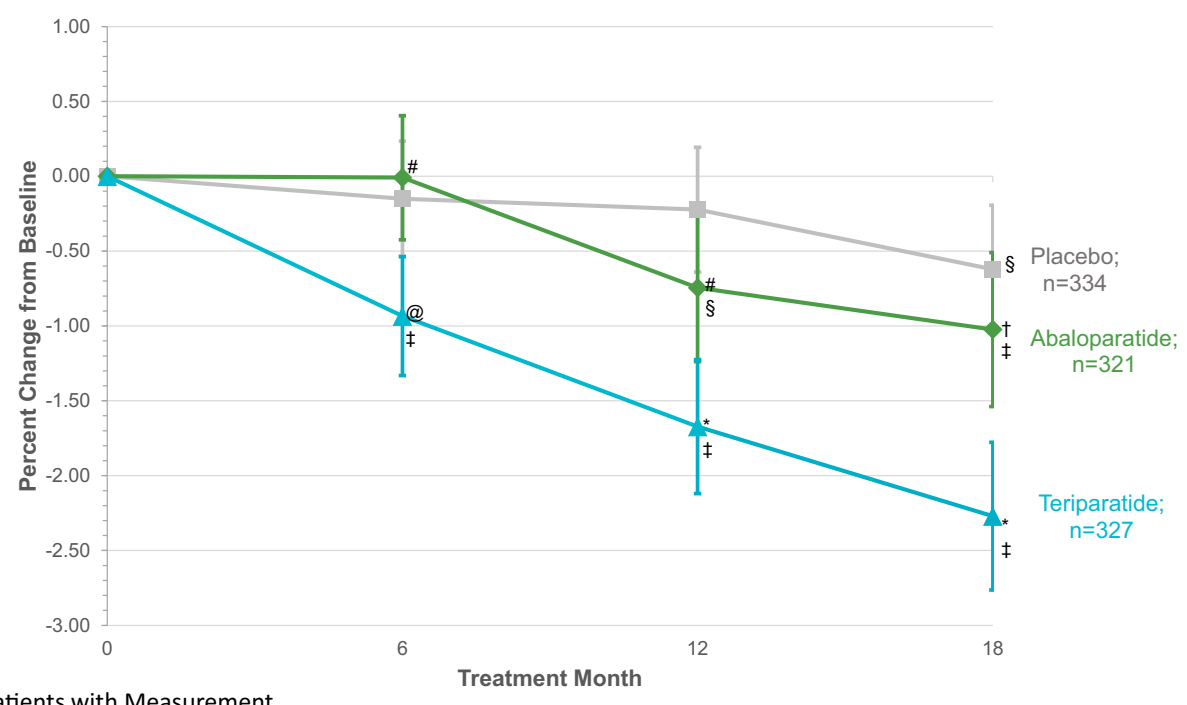

No. of Patients with Measurement

$\begin{array}{lllll}\text { Placebo } & 334 & 316 & 280 & 268 \\ \text { Abaloparatide } & 321 & 290 & 256 & 241 \\ \text { Teriparatide } & 327 & 306 & 287 & 274\end{array}$

Fig. 2 


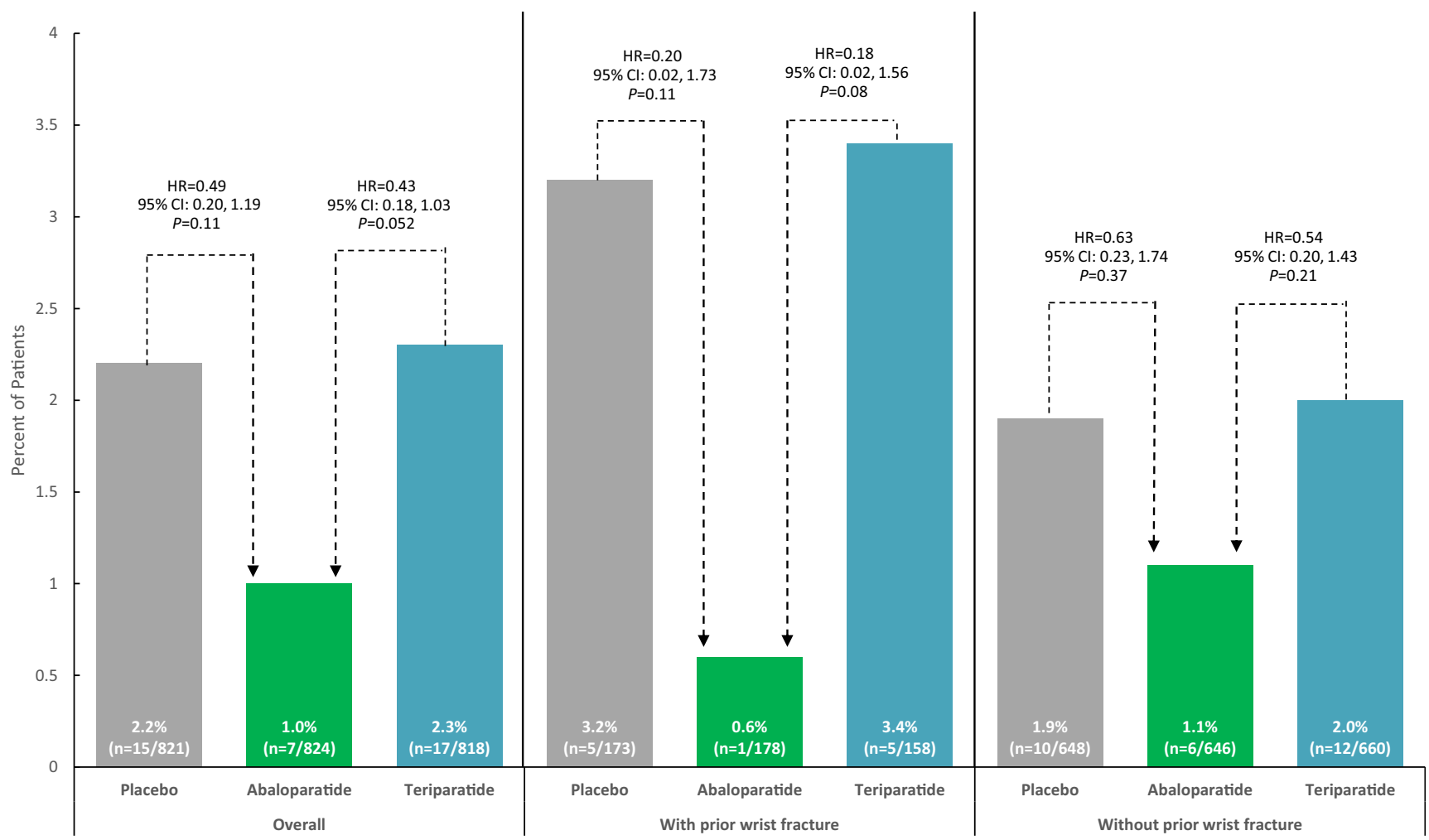

Fig. 3

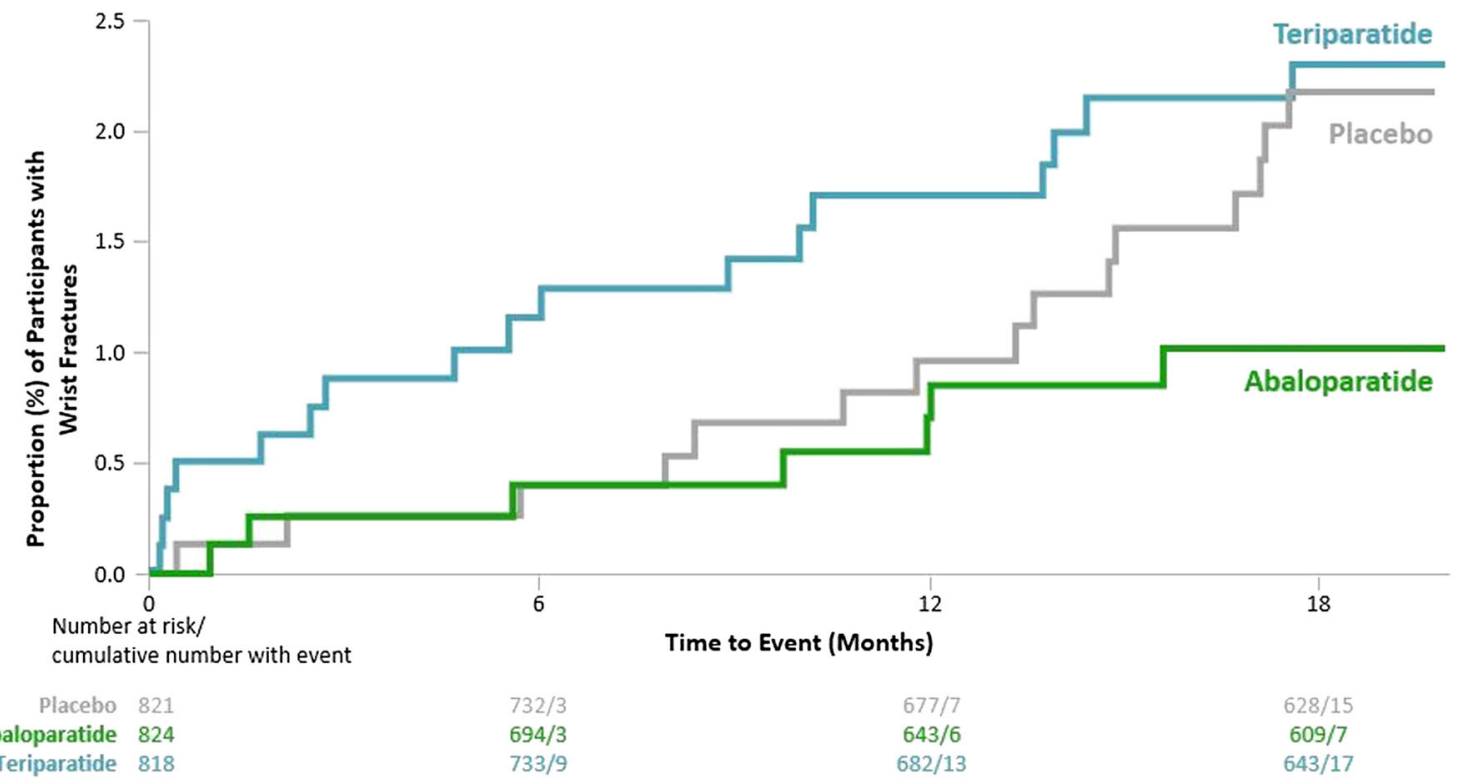

Fig. 4

Open Access This article is licensed under a Creative Commons Attribution-NonCommercial 4.0 International License, which permits any non-commercial use, sharing, adaptation, distribution and reproduction in any medium or format, as long as you give appropriate credit to the original author(s) and the source, provide a link to the Creative Commons licence, and indicate if changes were made. The images or other third party material in this article are included in the article's Creative Commons licence, unless indicated otherwise in a credit line to the material. If material is not included in the article's Creative Commons licence and your intended use is not permitted by statutory regulation or exceeds the permitted use, you will need to obtain permission directly from the copyright holder. To view a copy of this licence, visit http:// creativecommons.org/licenses/by/4.0/.

Publisher's note Springer Nature remains neutral with regard to jurisdictional claims in published maps and institutional affiliations. 